\begin{tabular}{|cc|c|}
\hline ISSN (Online): 2367-6957 & ISSN (Print): 2367-6361 \\
Izvestiya Journal of Varna University of Economics 4 (2020) & I Z V E S T I Y A \\
Journal of Varna University of Economics \\
http://journal.ue-varna.bg
\end{tabular}

\title{
RELEVANCE OF ENTREPRENEURIAL ORIENTATION STRATEGY TO COOPERATIVE BUSINESS ORGANIZATIONS IN NIGERIA
}

\author{
Nurudeen Afolabi SOFOLUWE ${ }^{1}$
}

${ }^{1}$ Department of Cooperative and Rural Development, Olabisi Onabanjo University, Ago-Iwoye,
Ogun State, Nigeria. E-mail: nasofoluwe@gmail.com JEL: J54, L25

\begin{abstract}
This study examines the relevance of entrepreneurial orientation (EO) strategies to the success of cooperative business organizations. Primary data were collected through structured questionnaire from randomly sampled cooperative organizations. The data covered organizational characteristics, entrepreneurial orientation and performance of the cooperative firms. Descriptive analysis and structural equation model (SEM) were used to analyze the data. The findings show that entrepreneurial capacity of cooperative organizations to unlock prevailing market strategies is high. However, their level of aggressiveness for enhanced market competitiveness is low. Strong proclivity for high risk business is also low. The competitive aggressiveness of cooperative organization is found to be non-existent in the entrepreneurial framework. The
\end{abstract}

Key words:

Cooperatives, entrepreneurial orientation, market competition, SEM.

(C) 2020 University of Economics - Varna

Citation: SOFOLUWE, N. A. (2020). Relevance of Entrepreneurial Orientation Strategy to Cooperative Business Organizations in Nigeria. Izvestiya Journal of Varna University of Economics, 64 (4), p. 415 - 429. DOI: 10.36997/IJUEV2020.64.4.415

\section{Introduction}

Increasing changes in business environments and unpredictable reactions of individuals and customers alike make the task of survival of cooperative organizations more difficult. The pressure of globalization and market competition 
also suggest the need for various organizations to seek new ways of adapting to emerging business circumstances. One of the possible ways of surviving competition is to strategically utilize internal resources. As part of the strategic process, entrepreneurial orientation has been suggested as a viable and strategic means of achieving competitive success in organizations (Divito \& Bohnsack, 2017; Homaid, Minai \& Al-Ansi, 2018). Yet, it is not clear whether cooperative organizations could be advised to take advantage of this strategic option, most especially in developing economies. This is largely due to lack of information on the relevance of entrepreneurial orientation to successful outcome of cooperative organizations. Available evidence indicates that cooperative business organizations are built on effective business structure similar to other form of businesses (Adrian \& Green, 2001; Nunez \& Moyano, 2004; Agirre, Reinares \& Agirre, 2014; Affendy, AbdulTalib, \& Farid, 2015). But, in comparison to other forms of businesses, there is need for cooperative firms to create entrepreneurial orientation to achieve sustainable competitive advantage. Globally, the cooperative sector represents a significant contribution to the global economy. According to ICA (2018), the top 300 cooperatives around the world had a total turnover of over two trillion US dollars (\$2trillion). This is only close to the economy of the World's $8^{\text {th }}$ and $9^{\text {th }}$ largest economy, Italy and Brazil respectively. In each of these countries, cooperatives' development is largely championed by states and provinces. In Africa, almost 250,000 Kenyans are directly employed by cooperatives while over $63 \%$ of their population derived their livelihood from cooperative action.

Cooperative organizations as they exist in Nigeria show that cooperatives are associations of members with specific interest in promotion of member-patrons through provision of best possible services at minimum price (cost) (Ogunmuyiwa \& Sofoluwe, 2019). Although surpluses in the cooperative system are distributed in proportion to transactions of members, shares in the system are held exclusively by members and are not transferable unlike investors owned firms (Sofoluwe, 2019).

Traditionally, cooperatives are set up to assist member-patrons raise profits accruable from businesses. Consequently, cooperatives hold the outlook of an enterprise that exists based on 'user-owned' and 'user controlled' structure. By implication, both business and non-business activities of cooperatives are jointly owned and managed by all the members through democratic process. Furthermore, benefits from transactions of cooperatives are also distributed equitably among the members based on the patronage (Ogunmuyiwa \& Sofoluwe, 2019). The goal of the study is to empirically examine the relevance of entrepreneurial orientation to the success of cooperative business entities. Due to prevailing economic circumstances in 
Nigeria, and the stringent conditions associated with access to credits, most individuals at medium to lower class of Nigerian society depend on supports from cooperative organizations. Hence, the business success of cooperative groups has both direct and indirect consequence on survival of most people. Given that there is limited literature examining entrepreneurial orientation and performance of cooperative business organizations, we seek to add to frontier of knowledge on empirical link between entrepreneurial orientation (EO) and performance of cooperative organizations. While a number of studies exist on $\mathrm{EO}$ of other forms of businesses, little has been found to on the role of EO in driving cooperative businesses.

The rest of the paper is organized in sections. The next section presents relevant literature on EO, cooperative business organizations and the empirical evidence between EO and various forms of businesses. The third section covers the methodology of the study while the following section discusses the results. The last section concludes the paper.

\section{Literature review}

Studies examining the relationship of EO to cooperative business firms are scarce. However, most existing studies on entrepreneurial activities of firms have relied on the theory of entrepreneurship. In a competitive process, EO could be a key determinant of the ability of a firm to survive competition. It may also be an important factor in gaining new opportunities and differentiate a business organization from others. Consequently, EO has attracted different forms of definition. Early scholars including Dunkelberg and Cooper, (1982) described it as attributes and values that bring up motivation to succeed through entrepreneurial actions. Dess and Lumpkin (2001) associate EO with a path leading to a new entrance, while Wiklund and Shepherd (2003) believed it is simply a strategy of a firm involving certain processes and practices with a view to surviving competition. It is a tool to align organizational vision with market realities. It is a business organization attempt to be creative through introduction of new products or services (Anderson et al., 2015). Based on these definitions, business organizations with EO could gain huge capabilities to make discoveries and take risk with new market opportunities (Lee, Lee \& Pennings, 2001).

A number of studies have viewed EO from business perspective. Alarifi, Robson and Kromidha (2019) considered it crucial to breaking market complexities, gaining new business ground and establishing product needs of numerous people. Divito and Bohnsack (2017) investigated the interaction effect between entrepreneurial 
orientation and sustainability decision. Exploratory and mixed methods were applied to different dimensions of EO. The findings show that EO could affect sustainability decision making in different forms. The importance of this study lies in its theoretical application. The application to business firms remains unexplored. The earlier study conducted by Anderson et al. (2015) attempted to redefine EO constructs focusing on nomological error in the EO literature. The study suggested a need for decomposition into behavioural and attitudinal components of EO. Alarifi et al. (2019) examined the relevance of EO to social enterprises. The findings indicate that performance of social firms is significantly linked to innovation and proactiveness. However, the study did not find significant support for risk taking as a component of EO in the development of social enterprises.

Lumpkin and Dess (2001) contended that EO is grossly associated with the ability of an organization to take risks, be proactive in taking innovative decisions and achieve success among competitors. Consequently, studies (e.g. Lurtz \& Kreutzer, 2016; Beekman, Steiner \& Wasserman, 2012; Wilkund \& Shepherd, 2005; Li et al., 2009) showed that EO is an organizational survival strategy that is capable of raising performance level of business organizations. In order to benefit from advantages inherent in EO, it is important for business organizations to understand and apply its various dimensions.

These dimensions include 'risk taking', 'proactiveness', 'innovation', 'advancement', 'competitive aggressiveness', and 'autonomy' (Lurtz \& Kreutzer, 2016; Lumpkin \& Dess, 2001). These dimensions are not without criticism. Homaid et al. (2018) agreed with only three of the dimensions - risk, innovation and proactiveness but Ireland et al. (2003) argued that the additional dimensions of EO can bring about market growth rate. Nonetheless, it is almost a consensus that part - if not all of the dimension constructs are crucial to success. This suggests that for a business organization to outperform its competitors, some of the key dimensions of EO, if not all, need to be put in perspective.

In the study conducted by Homaid et al. (2018), strategic orientation variables such as market orientation, entrepreneurial orientation and learning orientation were examined in relation to the performance of microfinance institutions. The findings of the study showed that EO has a significant effect on the performance of microfinance firms. Since microfinance institutions are finance based, the application of the findings to other non-strict financial firms may be limited.

The performance of organizations is generally addressed from two perspectives: financial and non-financial measures (Alarape, 2013). Financial measures of performance include firm revenue, return on investment (ROI), return on assets 
(ROA) and return on equity (ROE). But the use of financial variables to capture performance is better carried out using time series data to reflect the trend and variations in financial variables over time. Consequently, performance using financial variables is criticized on the basis of that limitation. Non-financial measure of performance usually covers customer satisfaction, market share, loyalty, sales growth, patronage. The limitation of this type of measure is that it is usually very subjective to the perception of the respondents. Yet, in situation where data over a large period of time are not available, non-financial performance is usually better to capture organizational outcome at a point in time.

\section{Methodology}

The study adopts a questionnaire survey. All items of the questionnaire are captured in Likert-form (five-point) responses that ranged from ' 1 to 5 '. The response are measured as "strongly agree" $=5$, 'agree' $=4$, 'neutral' $=3$, 'disagree' $=2$ and 'strongly disagree' $=1$. The study population covers cooperative business enterprises registered under the existing law of the Nigerian cooperative societies Act. 850 questionnaires were distributed to randomly sampled respondents out of which 636 $(74.8 \%)$ were found useful. Data collected included characteristics of the organization, measures of entrepreneurial orientation and performance. Reliability measures were set at a minimum recommended standard of 0.60 (Nunnaly, 1978). Measures of EO were adapted from previous studies (Li et al., 2009; Lumpkin \& Dess, 2001; Alarape, 2014). The EO measures cover several constructs under five dimensions of innovativeness, risk taking, proactiveness, competitive aggressiveness, and autonomy. In order to account for variation in sizes of the cooperative organizations, 'annual growth rate in asset' of the organizations is computed as a measure of performance (Alarape, 2013). The approach accounts for the bias created by cooperative organizations of dissimilar sizes. The mathematical expression of the performance measure is given as follows:

$$
\begin{aligned}
& Z_{t 1}=Z_{t o}(1+h)^{t 1-t 0} \\
& Z_{t o}(1+h)^{t 1-t 0}=Z_{t 1} \\
& (1+h)^{t 1-t 0}=Z_{t 1} / Z_{t 0} \\
& 1+h=\left(Z_{t 1} / Z_{t 0}\right)^{1 / t 1-t 0} \\
& h=\left(Z_{t 1} / Z_{t 0}\right)^{1 / t 1-t 0}-1
\end{aligned}
$$


$\mathrm{h}=$ growth rate of the cooperative organization (annual growth rate), $Z_{t 1}=$ cooperative assets at inception while $Z_{t 0}$ represents the value of assets at present. Structural equation model (SEM) in addition to descriptive statistics was used. Both SPSS and AMOS v. 23 were utilized to carry out the analysis. Measurement of items and reliabilities are presented in Tables 1 and 2. The Cronbach's Alpha test shows that most of the items of all the constructs are above 0.70 , suggesting that the items are at high level of internal consistency. The composite reliability is also high indicating the appropriateness of the constructs and the items to measure entrepreneurial orientation of cooperative business organizations.

Table 1

\section{Measurement of the study variables}

\begin{tabular}{|c|c|c|}
\hline \multicolumn{2}{|c|}{$\begin{array}{c}\text { EO Dimensions } \\
\text { Indicators } \\
\end{array}$} & Item measures \\
\hline \multirow[t]{6}{*}{ Innovativeness } & (inn1) & Cooperatives favours innovativeness of product. \\
\hline & (inn2) & New lines of product and service in the last 3 years \\
\hline & (inn3) & Emphasis on cooperative principles and values \\
\hline & (inn4) & Changes in new product ideas \\
\hline & (inn5) & Investment in R\&D in harsh economic conditions. \\
\hline & (inn6) & A unique approach to business \\
\hline \multirow[t]{6}{*}{ Proactiveness } & (pro1) & Business actions in market \\
\hline & (pro2) & Strong tendency to drive cooperative ahead of competitors \\
\hline & (pro3) & Unlocking the prevailing competitors' strategies \\
\hline & (pro4) & Increasing level of market aggressiveness \\
\hline & (pro5) & Continuous scanning of business environment \\
\hline & (pro6) & Market opportunities are frequently researched \\
\hline \multirow[t]{5}{*}{ Risk-taking } & (risk1) & Strong proclivity for high risk business \\
\hline & (risk2) & Intuitive actions in prevailing business environment \\
\hline & (risk3) & Bold decision with respect to services \\
\hline & (risk4) & Aggressiveness in decision taking \\
\hline & (risk5) & The culture of risk taking \\
\hline \multirow[t]{3}{*}{ Autonomy } & (aut1) & Independent actions to bring out an idea \\
\hline & (aut2) & Cooperative pursues self-directed opportunities \\
\hline & (aut3) & Independence of actions among Coop members \\
\hline \multirow[t]{2}{*}{ Aggressiveness } & (ca1) & Organization is reactionary to business trends \\
\hline & $(\mathrm{ca} 2)$ & Market changes attract aggressive behaviour \\
\hline
\end{tabular}

All items were measured on Likert scale (5-point). 


\section{Reliabilities of the study variables}

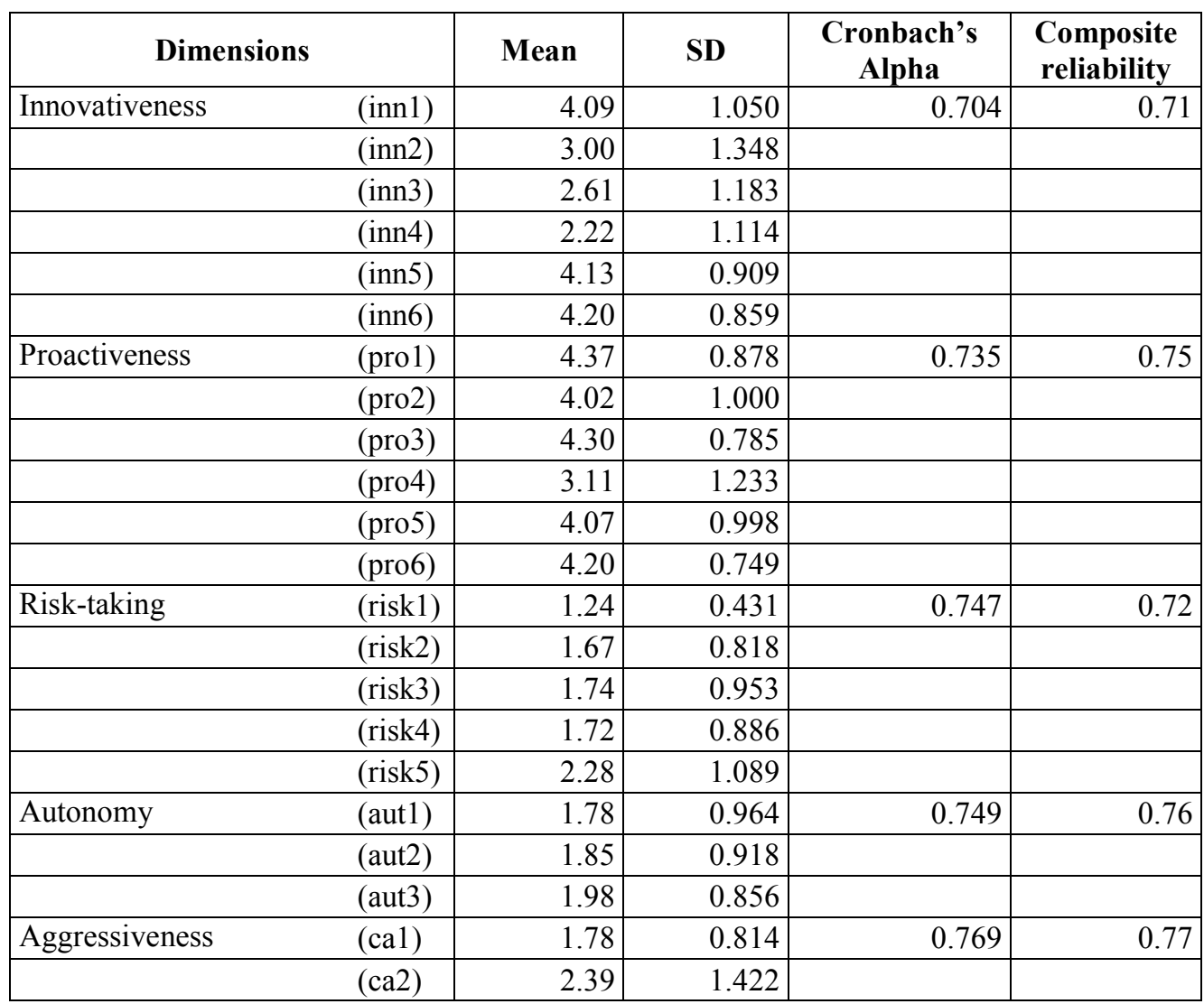

\section{Results and Discussion}

\subsection{Characteristics of respondents}

Characteristics of the sampled cooperative organizations are presented in Table 3. Less than $40 \%(39.15 \%)$ of the sample cooperatives engaged in produce marketing. Less than $30 \%$ of the sample focused on thrift, credit and investment activities while $16 \%$ are multi-purpose group engaging in diverse forms of activities. The rest of the sample is consumer cooperatives. The age of the cooperative group also differs. Most $(60 \%)$ of the organizations have years of establishment ranging between 5 and 10 ; $26 \%$ are above 10 years of existence while approximately $13 \%$ are less than 5 years. 
In terms of available capital for business activities, the majority (65.1\%) of the cooperative groups have capital accumulation value above $\$ 5,000,000(\$ 13,698.63)$. The percentage of cooperative groups with less than $\$ 1,369.863$ capital value is below 5\% (3.93\%). However, 22.8\% have capital accumulation value that ranges between $\$ 2,739.726$ and $\$ 13,698.63$.

Table 3

\section{Characteristics of cooperative firms}

\begin{tabular}{llr}
\hline \multicolumn{1}{c}{ Firm characteristics } & \multicolumn{1}{c}{ Items } & Frequency (\%) \\
\hline Types & Thrift, Credit and investment & $186(29.25)$ \\
& Consumer & $98(15.41)$ \\
& Multi-purpose & $103(16.19)$ \\
& Produce-marketing & $249(39.15)$ \\
\hline Age (years) & $<5$ & $82(12.89)$ \\
& $5-10$ & $383(60.22)$ \\
& $>10$ & $171(26.89)$ \\
\hline Capital (\$000) & $<500(\$ 1369.86)$ & $25(3.93)$ \\
& $500-1000$ & $52(8.18)$ \\
& $(\$ 1369.86-2739.73)$ & $145(22.80)$ \\
& $1000-5000$ & $414(65.09)$ \\
\hline
\end{tabular}

Source: Field Survey, 2019.

\subsection{Entrepreneurial orientation strategies and performance of cooperatives}

The diagnostics of the SEM as indicated by indices of goodness-of-fit indicate appropriateness of the specification (Table 4). The Chi-square/degree of freedom ratio of the model is 2.19 and this value falls within the expected range of 1 and 5. A lower value of the ratio usually suggests a good fit of the specification. The values of the remaining indices of the model are higher than the commonly used threshold level of 0.90 , suggesting the fit of the model specification. Also, the estimated value of root mean square error of approximation (RMSEA) is 0.063 which is lower than the maximum value of 0.08 . 
Table 4

\section{Goodness of fit indices of the structural equation model}

\begin{tabular}{lll}
\hline \multicolumn{1}{c}{ Goodness of fit indices } & \multicolumn{1}{c}{ Construct } & \multicolumn{1}{c}{ Reference Value } \\
\hline$\chi^{2} /$ degree of freedom & 2.190 & $1<\chi^{2} / \mathrm{df}<5$ \\
CFI(Comparative Fit Index) & 0.971 & $0.95<\mathrm{CFI}<1$ \\
NFI (Normed Fit Index) & 0.923 & $0.90<\mathrm{NFI}<1$ \\
RFI (Relative Fit Index) & 0.919 & $0.90<\mathrm{RFI}<1$ \\
IFI (Incremental Fit Index) & 0.967 & $0.95<\mathrm{IFI}<1$ \\
TLI(Tucker-Lewis Fit Index) & 0.933 & $0.95<\mathrm{TLI}<1$ \\
RMSEA (Root Mean Square Error) & 0.063 & $\mathrm{RMSEA}<0.08$ \\
\hline
\end{tabular}

Source: Data Analysis, 2019.

The path analysis of the SEM from the structural equation is graphically represented in Figure 1. The squared multiple correlation (SMC) values of each 'innovative' constructs indicate that 'innl' is 0.22 implying that $22 \%$ of the variance in cooperative innovativeness is represented by their drive for development and leadership (inn 1). Innovativeness in the aspect of creating 'a new line of product and service over the last 3 years' (inn2) has SMC value of 0.535 indicating that $53.5 \%$ of variance in innovativeness of cooperatives could be associated with 'inn2'. The innovative drive of cooperative organizations appears to be largely based on cooperative principles and values (inn3). The SMC value is higher at 0.665 indicating that about $67 \%$ of entrepreneurial idea that centres on innovation is largely derived from principles and values of cooperatives. The SMC value for 'inn4' is 0.338 suggesting that innovative 'changes are incorporated in new product ideas' by cooperative at $33.8 \%$ level. SMC values for 'inn5' and 'inn6' are below 1\% (0.004 and 0.001), an indication that cooperative organizations do not 'favour research investment in development during harsh economic conditions' (inn5) and that cooperatives do not 'adopt a unique approach to business production' (inn6). Intuitively, out of the six factors measuring variances in innovativeness, only four are applicable to cooperative business organizations. These are emphasis on research and development, establishment of new lines of product and service, application of principles and values of cooperative organization, and changes to the cooperative ideas.

The entrepreneurial proactiveness of organizations is defined by a number of factors. The squared multiple correlation values of the factors show different level of variances. The value of 'prol' is 0.629 indicating that about $63 \%$ of the variance in proactiveness of cooperative organization is associated with its capacity to initiate 
business actions in the prevailing market (pro1). The factor of 'pro2' shows squared multiple correlation value of 0.314 , and indication that the tendency to drive cooperative organizations ahead of investors owned business is just $31.4 \%$ of the variances in entrepreneurial proactiveness of the organizations. The entrepreneurial capacity of cooperative organizations to unlock prevailing market strategies (Pro3) is high at 0.670 representing $67 \%$ of the variances in entrepreneurial proactiveness. However, the level of aggressiveness of cooperative organization for enhanced market competitiveness is low at $0.015(1.5 \%)$. This is an indication that entrepreneurial proactiveness of cooperative organization is not largely defined by its aggressiveness (pro4). A similar result is obtained for orientation of cooperatives toward frequent research for market opportunities (pro6). The estimated squared multiple correlation is $0.181(18.1 \%)$ of the variance in proactiveness of cooperative organizations. The tendency to scan business environment as part of entrepreneurial proactiveness is 0.404 . The result implies that about $40 \%$ of proactiveness of cooperative organization is linked to market scanning.

Strong proclivity for high risk business is very low since the result shows that less than $1 \%(0.5 \%)$ of the risk taking component in a cooperative organization is attributed to the factor of proclivity (risk1). The finding supports the proposition that the prevailing business environment brings about intuitive actions by cooperative organizations (risk2). Squared multiple correlation value of 0.620 is obtained indicating that over $60 \%$ of the variances in entrepreneurial risk of cooperative is linked to the environment and intuitive action of business groups. In terms of service provision, the findings suggest that risk taking attributes of cooperative organization is largely $(79.7 \%)$ linked to the organizational bold decision on service provision (risk3). The factor of aggressiveness in decision taking is relatively low (37.2\%) suggesting that much could not be attributed to the factors in the discussion on risk taking attributes of cooperative organizations. The question on existence of risk taking culture by cooperative could not be given full affirmative response since only $42.5 \%$ of the variance in risk taking is linked to the factors.

The analysis on autonomy variable show that autonomy of cooperative organization is largely represented by self-directed ability and wills of the organization (91.5\%) followed by independent action of members at 50.6\% level and independence of actions among cooperative members (46.9\%). An interesting results from the analysis is that the two constructs of competitive aggressiveness in a cooperative organization are both negative $(-0.009$ (ca2) and -0.208 (ca1)) suggesting near absence of competitive aggressiveness in entrepreneurial framework of cooperative organizations 


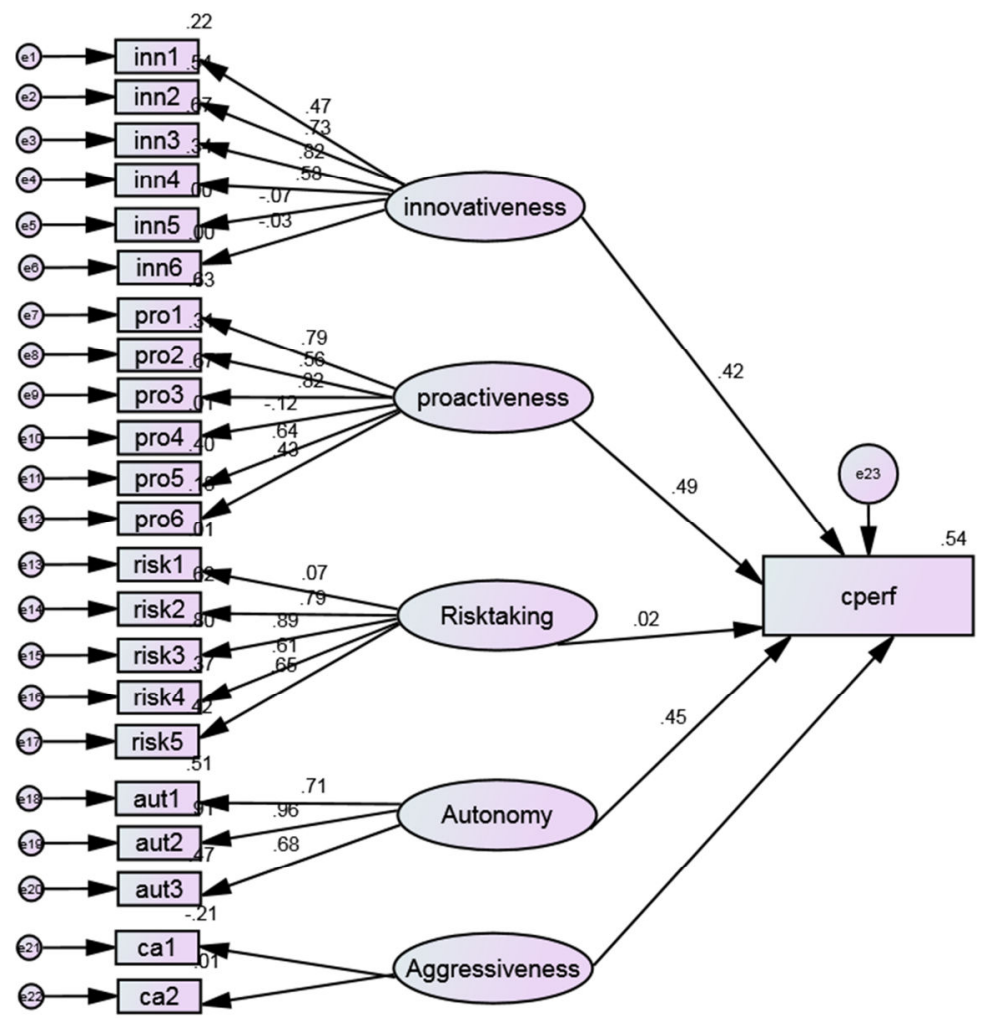

\section{Fig 1: Structural equation model}

With respect to the effect of entrepreneurial orientation, 'proactiveness' shows the largest effect on performance of cooperatives (0.49). This is followed by autonomy (0.45) and innovativeness (0.42) respectively. The effect of risk-taking dimension of EO on performance of cooperative is very low (0.02). Interestingly, there seems to be absence of competitive aggressiveness among cooperative groups. The estimation did not return regression weight value for the variable while the squared multiple correlation values for the two constructs of competitive aggressiveness (CA) were also negative. In order to affirm this result, a hypothesis was tested for the CA variable and was set up as follow:

$H_{o 1}$ : Competitive aggressiveness is non-existent in cooperative organizations

The result of the hypothesis using F-test of variance in a multi-regression process suggests that the null hypothesis $\left(H_{o l}\right)$ cannot be rejected. Hence, the result $(\mathrm{F}$ $=0.733, \mathrm{p}>0.05)$ affirmed that competitive aggressiveness is non-existent in 
cooperative business organizations. The result of the hypothesis testing is presented in Table 5.

Table 5

Test of hypothesis of competitive aggressiveness

\begin{tabular}{|l|l|r|r|r|r|}
\hline \multicolumn{2}{|l|}{ Model } & Sum of Squares & Mean Square & \multicolumn{1}{c|}{ F } & Sig. \\
\hline \multirow{3}{*}{1} & Regression & 1.445 & .723 & .733 & $.486^{\mathrm{b}}$ \\
\cline { 2 - 7 } & Residual & 42.381 & .986 & & \\
\cline { 2 - 7 } & Total & 43.826 & & & \\
\hline
\end{tabular}

Source: Data Analysis, 2019.

\section{Conclusions}

The findings of the study indicate that EO elements such as proactiveness, autonomy and innovativeness are relatively related to the performance outcome of cooperative business organizations. This is consistent with Wiklund and Shephered (2005). If the strategic success of cooperative business entities rests on its proactiveness, autonomy and innovativeness, it would be more appropriate to direct policy actions towards improving entrepreneurial orientation of these firms toward these lines.

From the perspective of entrepreneurial orientation, the finding of this research suggests that risk-taking and competitive aggressiveness are not clearly related to the performance drive of cooperative organizations. This agrees with the findings of Affendy et al. (2015). The implication of the findings is that cooperative business organizations do not have strong proclivity for high risk business. Also, the findings of the study suggest that cooperative firms exhibit low response to prevailing business challenges. Furthermore, the cooperative business organization is found to be less aggressive in decision making and the culture of risk is almost non-existent. The factors associated with competitive aggressiveness including swift reaction to market trends and changes are not part of entrepreneurial orientation of cooperative business organizations. Intuitively, cooperative organizations as it is in developing nations like Nigeria could not be relied upon to stimulate strong market reactions during economic crisis. Thus, the findings of the study lead to a conclusion that competitive aggressiveness is nearly absent as an entrepreneurial strategy of cooperative organizations.

The results of this study have significant implications for stakeholders of cooperative organizations and for other forms of business in general. There are greater indicators for these firms to nurture risk-taking ability and develop 
competitive aggressiveness. Global economic outlook is dynamic suggesting needs for adjustment to changes by all business firms. While adherence to cooperative principles and values as part of its autonomy supports greater performance, increase in entrepreneurial skills in a strategic way is needed to sustain greater level of performance. This study therefore confirms that only part of entrepreneurial orientation strategies is relevant to driving organizational performance of cooperative entities in a competitive environment.

At present, there is no supporting evidence to conclude that all the five dimensions of entrepreneurial orientation (innovativeness, proactiveness, risk-taking, autonomy and competitive aggressiveness) as espoused in some literature cannot be generalized for all business organizations. This conclusion finds support in some existing studies.

This study has its limitations. First, it covers only cooperative business organizations implying possibilities of variation for other forms of business. Second, it is carried out in developing nation with institutional limitations. Also, the data is cross-section which is largely subjective. Subjective measure of performance is not perfect. Future research could consider triangulation and also measure performance using different types of variables.

\section{References}

1. Adrian, J. L. and Green, T. W. (2001). Agricultural Cooperative Managers and the Business Environment. Journal of Agribusiness, 19(1), pp.17-33.

2. Affendy, A. H., Abdul-Talib, A., and Farid, M. S. (2015). Entrepreneurial Orientation Effects on Market Orientation and SMEs Business Performance - A SEM Approach, Review of Integrative Business \& Economics Research, 4(3), pp. 259-271.

3. Agirre, I., Reinares, P., and Agirre, A. (2014). Antecedents to Market Orientation in the Worker Cooperative Organization: The Mondragon Group, Annals of Public and Cooperative Economics, 85(3), pp. 387-408.

4. Alarape, A. A. (2013). Entrepreneurial orientation and the growth performance of small and medium enterprises in Southwestern Nigeria, Journal of Small Business \& Entrepreneurship, 26(6), pp. 553-577.

5. Alarifi, G., Robson, P., and Kromidha, E. (2019). The manifestation of entrepreneurial orientation in the social entrepreneurship context, Journal of Social Entrepreneurship, doi: 10.1080/19420676.2018.1541015.

6. Anderson, B. S., Kreiser, P.M., Kuratko, D. F., Hornsby, J. S and Eshima, Y. (2015). Reconceptualizing Entrepreneurial Orientation, Strategic Management Journal, 36, pp. 1579-1596 
7. Beekman, A. V., Steiner, S. and Wasserman, M. E. (2012). Where Innovation Does a World of Good: Entrepreneurial Orientation and Innovative Outcomes in Nonprofit Organizations, Journal of Strategic Innovation and Sustainability, 8(2), pp. 22-36.

8. Dess, G. G., and Lumpkin, G. T. (2001). Emerging Issues in Strategy Process Research. In: M. A. Hitt, R. E. Freeman, and J. S. Harrison, ed., The Blackwell Handbook of Strategic Management, 3rd-4th ed. Malden, MA: Blackwell, pp. 3-4

9. Dunkelberg, W. C., and Cooper, A. C., (1982). Entrepreneurial Typologies. In: K. H. Vesper, ed., Frontiers of Entrepreneurship Research, Wellesley, Babson: Centre for Entrepreneurial Studies, pp. 1-15.

10. Divito, L., and Bohnsack, R. (2017) Entrepreneurial orientation and its effect on sustainability decision tradeoffs: The case of sustainable fashion firms, Journal of Business Venturing, pp. 1-19, http://dx.doi.org/10.1016/j.jbusvent. 2017.05.002

11. Homaid, A. A., Minai, M. S., and Al-Ansi, A. A. (2018). The effect of market and entrepreneurial orientation on the performance of microfinance institutions: The mediating role of learning orientation in the context of Yemen, Journal of Business and Retail Management Research, 12 (3), pp. 126-139.

12. International Cooperative Alliance (2018). Retrieved from, https://www. ica.coop/en [Accessed 12 January, 2020].

13. Ireland, R. D., Hitt, M. A., and Sirmon, D. G. (2003). A model of strategic entrepreneurship: The construct and its dimensions. Journal of Management, 29(6), pp. $963-989$.

14. Lee, C., Lee, K., and Pennings, J. M. (2001). Internal capabilities, external networks, and performance: A study on technology-based ventures. Strategic Management Journal, 22(6-7), pp. 615-640.

15. Li, Y., Huang, J., and Tsai, M. (2009) Entrepreneurial orientation and firm performance: The role of knowledge creation process, Industrial Marketing Management, 38, pp. 440-449

16. Lumpkin, G. T., and Dess, G. G. (2001). Linking Two Dimensions of Entrepreneurial Orientation to Firm Performance: The Moderating Role of Environment and Industry Life Cycle. Journal of Business Venturing, 16: 429-451.

17. Lurtz, K., and Kreutzer, K. (2016). Entrepreneurial Orientation and Social Venture Creation in Nonprofit Organizations: The Pivotal Role of Social Risk Taking and Collaboration, Nonprofit and Voluntary Sector Quarterly, pp. 1-24.

18. Nunez M. and Moyano J. (2004). Ownership structure of cooperatives as an environmental buffer. Journal of Management Studies, 41(7), pp. 31-52. 
19. Nunnally, J. C. (1978). Psychometric theory. New York: McGraw-Hill.

20. Sofoluwe, N. A. (2019) Effect of democratic control and ownership dimensions on performance of agricultural cooperatives in rural Nigeria. Malaysian Journal of Cooperative Studies, 15, pp. 95-107.

21. Ogunmuyiwa, M. S., and Sofoluwe, N. A. (2019). Cooperative financing of Micro Scale Enterprises in Nigeria. Izvestiya Journal of Varna University of Economics, 63 (2), p. 117 - 132.

22. Wiklund, J., and Shepherd, D. (2005). Entrepreneurial orientation and small business performance: A configurational approach. Journal of Business Venturing, 20(1), pp. 71-91.

23. Wiklund, J., and Shepherd, D. (2003). Knowledge-Based Resources, Entrepreneurial Orientation, and the Performance of Small and Medium-sized Businesses. Strategic Management Journal, 24: 1307-1314. 